\title{
Mitral Valve Replacement and Remodeling of the Left Ventricle in Dilated Cardiomyopathy with Mitral Regurgitation. Initial Results
}

\author{
Luiz Boro Puig, Fábio Antonio Gaiotto, José de Lima Oliveira Júnior, Mirian Magalhães Pardi, \\ Fernando Bacal, Charles Mady, Fábio Fernandes, Giovanni Bellotti, José Antonio Franchini Ramires, \\ Sérgio Almeida de Oliveira \\ São Paulo, SP
}

\begin{abstract}
Objective - This study evaluated the effects of a new method of mitral valve replacement on left ventricular $(L V)$ remodeling and heart failure functional class.

Methods - Eight patients (6 men) with severe mitral regurgitation from end-stage dilated cardiomyopathy underwent surgery. Five patients were in functional class (FC) IV, 2 were in FC III and 1 was in FC III/IV. Age ranged from 33 to 63 years. Both the anterior and posterior leaflets of the mitral valve were divided into hemileaflets. The resultant 4 pedicles were displaced under traction toward the left atrium and anchored between the mitral annulus and an implanted valvular prosthesis. The beating heart facilitated ideal chordae tendineae positioning.
\end{abstract}

Results - All patients survived and were discharged from the hospital. After a mean follow-up period of 6.5 months (1-12 m), 5 patients were in FC I; 2 in FC I/II; and 1 in FC II. The preoperative ejection fraction ranged from $19 \%$ to $30 \%$ (mean: $25.7 \pm 3.4 \%$ ), and the postoperative ejection fraction ranged from $21 \%$ to $40 \%$ (mean: $31.1 \pm 5.8 \%$ ). Doppler echocardiography showed evidence of $L V$ remodeling in 4 patients, including lateral wall changes and a tendency of the LV cavity to return to its elliptical shape.

Conclusion - This technique of mitral valve replacement, involving new positioning of the chordae tendineae, allowed $L V$ remodeling and improvement in FC during this brieffollow-up period.

Key words: dilated cardiomyopathy, left ventricular remodeling, mitral valve replacement

Instituto do Coração do Hospital das Clínicas - FMUSP

Mailing address: Luiz Boro Puig - InCor - Av. Dr. Enéas C. Aguiar, 44 05403-000 - São Paulo, SP - Brazil - lpuig@incor.usp.br

Received for publication on $8 / 30 / 01$

Accepted on 10/17/01
Functional mitral insufficiency (FMI) is not a rare complication of advanced dilated cardiomyopathy (DCM). It reflects changes in left ventricular (LV) geometry, the subvalvular apparatus, the mitral valve area and transvalvular pressures. Patients with DCM and FMI have refractory congestive heart failure and high mortality when in functional class (FC) III or IV. Blondhein et al ${ }^{1}$ reported survival rates over 32 months of $59 \%$ in patients with DCM without FMI, $26 \%$ in those with DCM and discrete FMI, and $17 \%$ in patients with DCM and moderate-to-severe FMI.

Although heart transplantation is the standard treatment for advanced DCM, the few available donor hearts are insufficient to supply all patients awaiting the organ. Stevenson et $\mathrm{al}^{2}$ reported a mortality rate of $46 \%$ per year in patients with an indication for cardiac transplantation who were waiting for a donor. Others are excluded from the organ waiting list because of advanced age or clinical contraindications.

Alternatives to heart transplantation have been proposed to improve quality of life and decrease mortality in these patients. FMI reflects the worst clinical evolution of DCM, and 2 techniques have been used to correct it. The first technique, mitral valve reconstruction, was proposed by Bolling et $\mathrm{al}^{3}$. This technique involves reduction of the dilated mitral annulus, thus, LV remodeling because of a decrease in the base diameter. The second technique, mitral valve replacement, was proposed by Buffolo et $\mathrm{al}^{4}$. This technique corrects valvular insufficiency and decreases LV base diameter. It involves implanting a small-diameter prosthesis and anchoring the 2 anterior valve hemileaflets, with their respective chordae tendineae, to the mitral annulus to assist the remodeling process.

We used mitral valve replacement to treat patients with DCM and FMI in this study. Our primary objective was to evaluate the short-term effects of valve replacement with new positioning of the chordae tendineae on $L V$ remodeling and FC. First, we altered the subvalvular apparatus to isolate 4 pillars with chordae tendineae, 2 from the anterior leaflet 
and 2 from the posterior leaflet. Then we anchored these 4 pillars and their associated chordae tendineae, under tension, to the mitral annulus to facilitate LV remodeling by the traction of papillary muscles on the ventricular wall. We compared pre- and postoperative echocardiographic and clinical data to determine the clinical utility of this technique.

\section{Methods}

Eight consecutive patients with severe LV systolic dysfunction, DCM, and FMI, who were receiving optimal medical therapy, underwent surgery at the Heart Institute of the Medicine Faculty Clinic's Hospital of São Paulo University from July 2000 to July 2001. All patients provided informed consent and the study was conducted in accordance with institutional guidelines. A prospective analysis was carried out using clinical and echocardiographic data from their postoperative course.

Six patients $(75 \%)$ were male and $2(25 \%)$ were female. The mean patient age was 51 years (range: 33 to 63 years). Upon hospital admission, 5 patients $(62.5 \%)$ were in heart failure functional class (FC) IV, $2(25 \%)$ were in FC III and 1 $(12.5 \%)$ was in FC III/IV. All patients included in this study had left ventricular ejection fraction $(\mathrm{EF}) \leq 30 \%$.

Six patients were being followed for idiopathic cardiomyopathy, one for postpartum cardiomyopathy and one for coronary artery disease. Two patients were excluded from the transplantation wait list because of renal failure requiring dialysis (cases 2 and 3) and/or a psychiatric disturbance (case 3) (tab. I). The number of hospital admissions due to congestive heart failure for these patients in the past 12 months was $5.6 \pm 3.8$ (range: 3 to 10 ). Three patients were in the intensive care unit (ICU) in cardiogenic shock at the time of surgery.

Pre- and postoperative transthoracic echocardiographic examinations were performed to evaluate the degree of

\begin{tabular}{|c|c|c|c|c|c|}
\hline \multicolumn{6}{|c|}{ Table I - Patient characteristics } \\
\hline Sex & Age (y) & FC & $\mathrm{EF} \%$ & \multicolumn{2}{|c|}{$\begin{array}{l}\mathrm{N}^{\circ} \text { of previous Etiology } \\
\text { hospital admissions }\end{array}$} \\
\hline M & 51 & IV & 24 & 6 & $\begin{array}{c}\text { Idiopathic } \\
\text { cardiomyopathy }\end{array}$ \\
\hline $\mathrm{F}$ & 57 & IV & 25 & 5 & $\begin{array}{c}\text { Idiopathic } \\
\text { cardiomyopathy }\end{array}$ \\
\hline M & 60 & III & 25 & 4 & $\begin{array}{c}\text { Idiopathic } \\
\text { cardiomyopathy }\end{array}$ \\
\hline M & 42 & IV & 19 & 6 & $\begin{array}{l}\text { Ischemic heart } \\
\text { disease }\end{array}$ \\
\hline M & 63 & IV & 30 & 7 & $\begin{array}{c}\text { Idiopathic } \\
\text { cardiomyopathy }\end{array}$ \\
\hline M & 46 & IV & 28 & 10 & $\begin{array}{c}\text { Idiopathic } \\
\text { cardiomyopathy }\end{array}$ \\
\hline $\mathrm{F}$ & 33 & III & 29 & 4 & $\begin{array}{c}\text { Postpartum } \\
\text { cardiomyopathy }\end{array}$ \\
\hline M & 56 & III/IV & 26 & 3 & $\begin{array}{l}\text { Idiopathic } \\
\text { cardiomyopathy }\end{array}$ \\
\hline \multicolumn{6}{|c|}{$\begin{array}{l}\text { FC- heart failure functional class (NYHA); EF- left ventricular ejection } \\
\text { fraction; y- years. }\end{array}$} \\
\hline
\end{tabular}

mitral insufficiency and LV function in all patients. Transesophageal echocardiography was performed during the operations. Hemodynamic parameters were derived from a Swan-Ganz catheter before and after the cardiopulmonary bypass and on the $2^{\text {nd }}$ and $3^{\text {rd }}$ postoperative days. Patients were only using intermittent vasodilator and diuretics drugs and no more than $5 \mathrm{mcg} / \mathrm{kg}$.min of dobutamine at these times.

Measures were compared via simple univariate statistical analysis, using the Student $t$ test, and, when necessary, the chi-square test. A p value of $<0.05$ was considered statistically significant.

Surgical technique - The patients were operated on via median thoracotomy. Normothermic cardiopulmonary bypass was established using membrane oxygenators. Myocardial protection was achieved with anterograde normothermic sanguineous cardioplegia associated with coronary reperfusion, whenever the surgical time permitted.

In most cases, the mitral valve was accessed via incision of the right atrium, roof of the left atrium and atrial septum, as described by Guiraudon et $\mathrm{al}^{6}$. The mitral anterior leaflet was sectioned in half from the valve annulus to the commissural areas. The resulting hemileaflets constituted 2 pillars with all of the chordae tendineae of the anterolateral and posteromedial papillary muscles. The other 2 pillars, formed by fragments of the sectioned posterior leaflet, had the most important chordae tendineae of the 2 papillary muscles (fig. 1).

The suture lines helped to anchor the prosthesis and the 4 pillars in a convenient position that was in accordance with the direction of the papillary muscles and would allow equal dispersion of forces. In this position, the pillars were held between the annulus and the prosthesis. The length of excess chordae was exteriorized to the left atrium while traction and adequate tension on the papillary muscles were maintained (fig. 2). The beating heart facilitated ideal chordae tendineae positioning, which was designed to maintain tension on the papillary muscles.

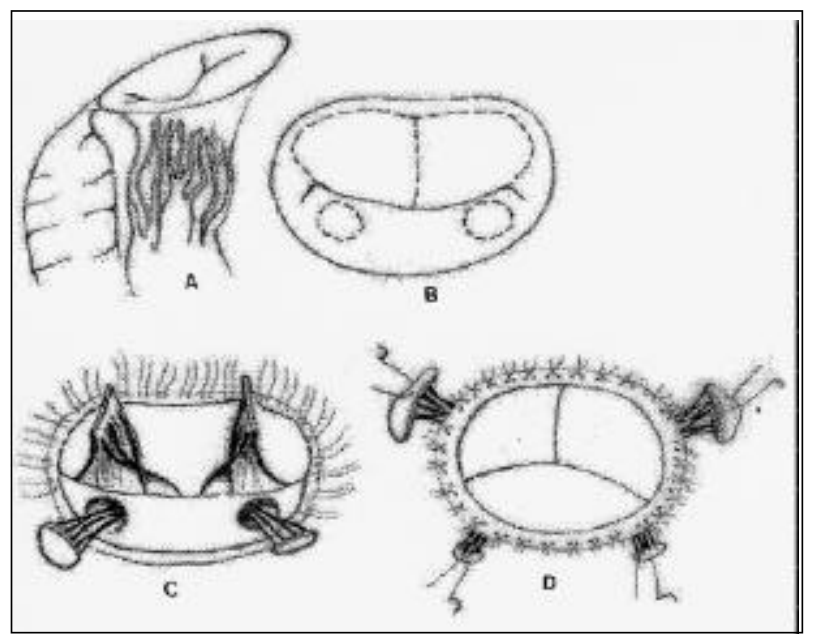

Fig. 1 - Schematic presentation of the surgical technique. A) Mitral valve. B) Mitral valve observed through the left atrium, showing the place of the section of the cusps. C) The 4 pillars. D) Mitral prosthesis on mitral ring with the 4 pillars. 


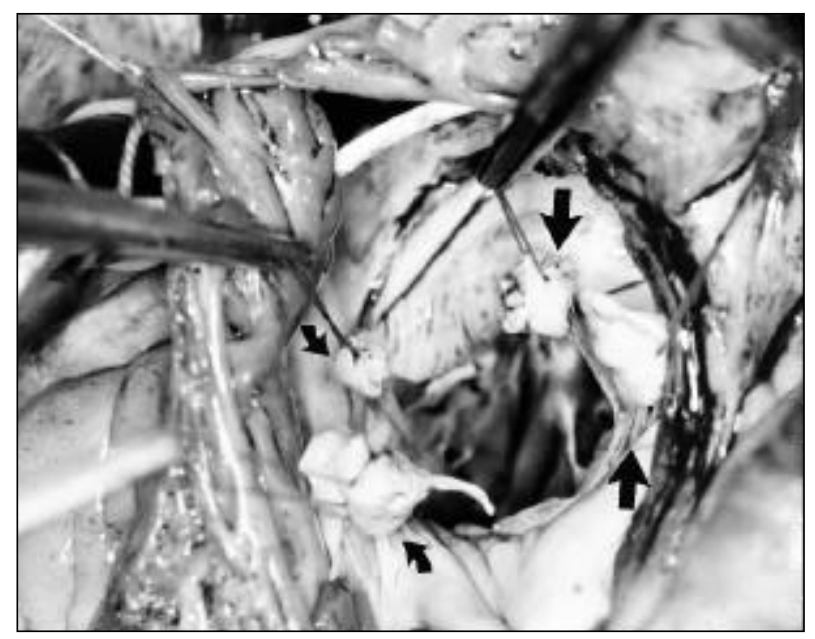

Fig. 2 - The large and small arrows, respectively, indicate the pillars of the anterolateral and posterolateral papillaries muscles.

\section{Results}

Bioprostheses, consisting of 5 porcine valves and 3 bovine valves, were implanted in all patients. We used a prosthesis with a diameter that was less than usual in each patient. We used a number 27 valve in 2 cases, 29 in 5 cases, and 33 in 1 case; the latter patient had undergone mitral reconstruction in the past year. Additional procedures were carried out in 3 patients consisting of aortic valve replacement (case 2), tricuspid valve reconstruction (case 3 ) and coronary artery bypass grafting (case 4 ).

The cardiac index (CI) ranged from 1.3 to 3.5 (mean: $2.3 \pm 0.71) \mathrm{L} / \mathrm{min} . \mathrm{m}^{2}$ preoperatively and from 3.6 to 5.8 (mean: $4.78 \pm 0.76$ ) $\mathrm{L} / \mathrm{min} . \mathrm{m}^{2}$ postoperatively (tab. II). Comparison of these data revealed a significant increase in $\mathrm{CI}(\mathrm{p}<0.0001)$ after the procedure. The cardiac output $(\mathrm{CO})$ and left ventricular EF also increased significantly postoperatively. The preoperative $\mathrm{CO}$ ranged from 2.2 to 4.7 (mean: $3.31 \pm 0.83$ ) $\mathrm{L} / \mathrm{min}$ and the postoperative $\mathrm{CO}$

\begin{tabular}{|lcc|}
\hline \multicolumn{3}{|c|}{ Table II - Preoperative and postoperative hemodynamic } \\
measurements
\end{tabular}

ranged from 5.7 to 6.9 (mean: $6.22 \pm 0.4) \mathrm{L} / \mathrm{min}(\mathrm{p}=0.0001)$. The EF ranged from $19 \%$ to $30 \%$ (mean: $25.7 \pm 3.4 \%$ ) preoperatively and from $21 \%$ to $40 \%$ (mean: $31.1 \pm 5.8 \%$ ) postoperatively ( $\mathrm{p}=0.003)$ (tab. III) (fig. 3).

In regard to geometry, a tendency toward reduction in the LV end-diastolic diameter was observed. This diameter ranged from 64 to 84 (mean: $71 \pm 6.6$ ) $\mathrm{mm}$ preoperatively and from 62 to 81 (mean: $69 \pm 7.2$ ) mm postoperatively ( $\mathrm{p}=0.081)$ (tab. III). The LV end-systolic diameter significantly decreased after the surgery, ranging from 53 to 75 (mean: $61.8 \pm 7.3$ ) $\mathrm{mm}$ preoperatively and from 46 to 68 (mean: $57.2 \pm 8.2) \mathrm{mm}$ postoperatively $(\mathrm{p}=0.0008)(\mathrm{tab} . \mathrm{III})$ (fig. 4, 5, and e 6).

All patients were discharged from the hospital and subsequent admissions for heart failure were not recorded. The follow-up time ranged from 1 to 12 months (mean: 6.5). All patients experienced significant improvement in their heart failure FC, with FC decreasing by 1 to 3 steps per patient (tab. IV). Thus, patients required less medication postoperatively than preoperatively. After the surgery, 5 (62.5\%) patients were in FC I, 2 (25\%) were in FC I/II, and 1 $(12.5 \%)$ was in FCII ( $\mathrm{p}=0.001)$ (tab. IV).

\begin{tabular}{|lcccccc|}
\hline \multicolumn{5}{|c}{ Table III - Preoperative and postoperative echocardiographic data } \\
\hline \multirow{2}{*}{ Patient } & LVEDD & \multicolumn{2}{c|}{ LVESD } & \multicolumn{2}{c|}{ EF\% } \\
& Pre & Post & Pre & Post & Pre & Post \\
\hline 1 & 78 & 78 & 71 & 67 & 24 & 29 \\
2 & 65 & 62 & 53 & 48 & 25 & 35 \\
3 & 76 & 68 & 67 & 61 & 25 & 28 \\
4 & 68 & 66 & 59 & 59 & 19 & 21 \\
5 & 64 & 64 & 53 & 46 & 30 & 40 \\
6 & 71 & 71 & 63 & 58 & 28 & 29 \\
7 & 65 & 62 & 58 & 51 & 29 & 36 \\
8 & 84 & 81 & 75 & 68 & 26 & 31 \\
M & $71 \pm 6.6$ & $69 \pm 7.2$ & $61.8 \pm 7.3$ & $57 \pm 8.2$ & $25.7 \pm 3.4$ & $31.1 \pm 5.8$ \\
P & \multicolumn{7}{|c}{0.081} & 0.0008 & & 0.003 \\
\hline
\end{tabular}

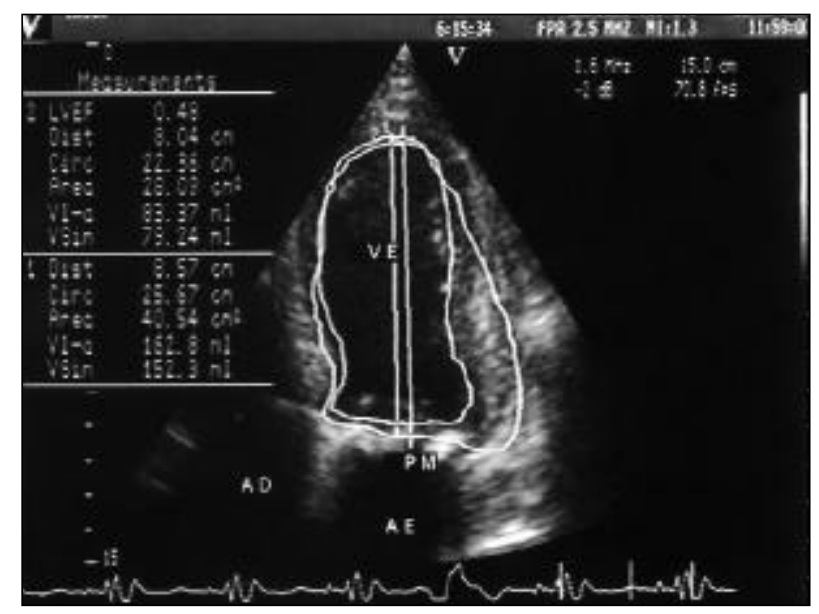

Fig. 3 - Diastolic and systolic aspect of the left ventricle after the surgery. 


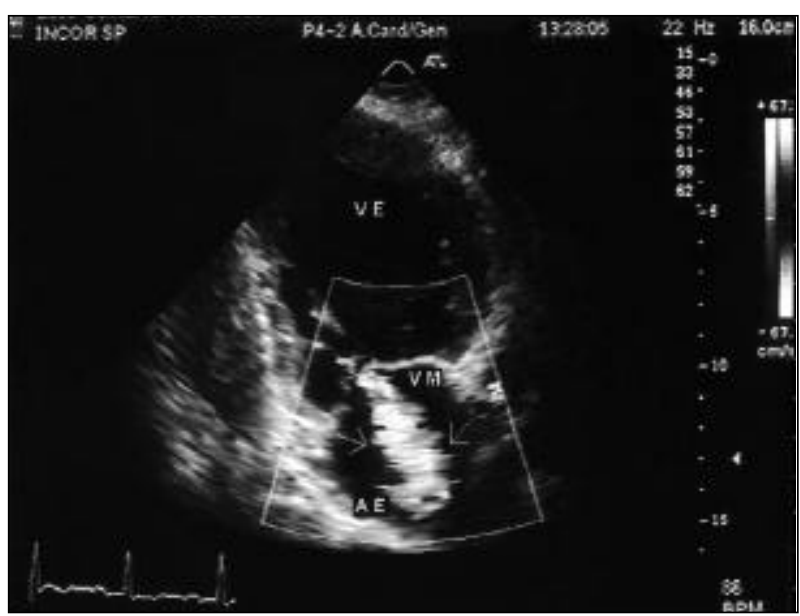

Fig. 4 - Mitral insufficiency by color Doppler (arrow).

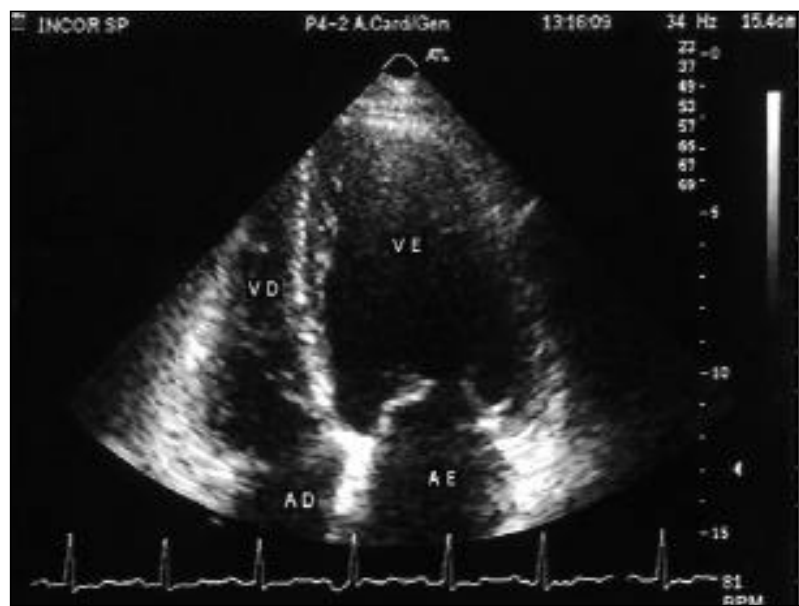

Fig. 5 - The preoperative transthoracic echocardiography evaluation of the dilated left ventricle.

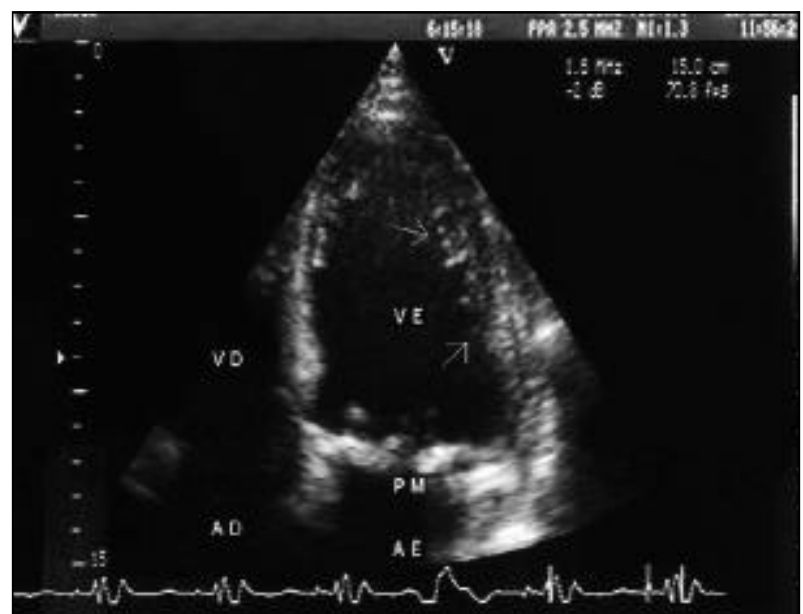

Fig. 6 - The preoperative appearance. Note the reduction of left ventricular cavity (arrows).

\section{Discussion}

Congestive heart failure is frequently observed in the final stages of cardiomyopathy, independent of the etiolo-

\begin{tabular}{|lcc|}
\hline \multicolumn{3}{|c|}{ Table IV - Clinical evolution } \\
\hline Patient & NYHA heart failure functional class \\
& Pre & Post \\
\hline 1 & IV \\
2 & IV & I \\
3 & III & II \\
4 & IV & I \\
5 & IV & I \\
6 & IV & I \\
7 & III & I/II \\
8 & III/IV & I/II \\
m & $3.6 \pm 0.5$ & I \\
p & & $1.4 \pm 0.5$ \\
& & 0.001 \\
NYHA- New York Heart Association. Preoperative and postoperative \\
clinical evaluation. The Student $t$ test was used for statistical analysis. \\
\hline
\end{tabular}

gy, contributing to a 1-year survival rate of $50 \%$ for patients in FC IV ${ }^{7,8}$. By clinical surveillance, Barreto and Ramires ${ }^{9}$ demonstrated that this pathology accounts for two thirds of the treatments for cardiovascular disease. When medical treatment does not afford sufficient improvement and the heart failure becomes refractory, surgical approaches can be used in selected cases to change the clinical evolution.

Heart transplantation is the ideal treatment for patients in FC III or IV. However, not enough donor hearts are available to meet patient demand. Furthermore, some patients die while on the organ waiting list ${ }^{10}$ or have contraindications to heart transplantation. Alternatives to transplantation have been used to improve survival and optimize clinical outcomes. These techniques include dynamic cardiomyoplasty ${ }^{11}$, myocardial revascularization in ischemic $\mathrm{DCM}^{12}$, partial left ventriculectomy ${ }^{13}$, biventricular pacemaker insertion ${ }^{14}$ and valve reconstruction ${ }^{3,15}$ or replacement ${ }^{4}$.

FMI is a negative development in the clinical evolution of DCM that increases patient mortality ${ }^{1}$. The valve leaflets do not undergo anatomic changes in DCM; however, changes of other structures cause dilatation of the mitral annulus and valve region. These changes include geometric disarrangement of the LV (ie, a tendency of the LV to become spherical), an increase in the size of the ventricular cavity, displacement of papillary muscle bases in posterolateral and apical directions and an increase in the heart base. The resultant dilation of the annulus and valve region does not permit the leaflets to remain together during ventricular systole and a rapidly progressive mitral insufficiency develops.

As symptoms of FMI increase, survival decreases. The FMI creates a volume overload in the dilated left ventricle. Thus, the LV diameter increases and the mitral annulus becomes more dilated. As the heart failure worsens, maximal medical treatment is used and the frequency of hospital admissions increases. The next stage is admission to the ICU because of cardiogenic shock.

Effective surgical correction of mitral valve insufficiency is imperative. The moderate blood volume that returns to the left atrium does not compromise cardiac output by a left ventricle with preserved and adapted function, but is deleterious in patients with DCM. In 
these patients, LV function is already pushed to its limit and the ventricle is without reserve power to adapt to mitral valve insufficiency.

Mitral reconstruction offers the attractive feature of preservation of the natural valve. With the decrease in the posterior part of the valve annulus and, therefore, the heart base, the mitral insufficiency is corrected. Thus, the left ventricle must acutely adapt to the change in diastolic volume, because reflux to the atrium no longer occurs. Although mitral valve reconstruction does not significantly alter the EF, an increase takes place in the effective cardiac output because the systolic volume is now anterograde. The residual valve insufficiency after mitral reconstruction ranges from $16 \%$ to $33 \%$, as reported by Bolling et $\mathrm{al}^{3,16}$. Calafiore et al ${ }^{17}$ observed some degree of mitral valve insufficiency in 27 of 29 patients who underwent valve reconstruction. Another factor that warrants consideration is that mitral valve reconstruction does not affect the subvalvular apparatus.

Mitral valve replacement should totally correct the valve insufficiency. Bufollo et $\mathrm{al}^{4}$ believe that the inconvenience of inserting a prosthetic device in these patients is irrelevant, despite the fact that the time of valve use exceeds the survival index. High mortality with valve replacement was observed by Lillehei et $\mathrm{a}^{18}$ when the chordae tendineae had been sectioned. In 1964, these authors proposed preservation of the chordae tendineae and maintenance of the continuity between the papillary muscles and mitral valve annulus. With this technique, the incidence of low-output states was reduced and postoperative mortality decreased from $37 \%$ to $14 \%$.

In 1988, Miki et al ${ }^{19}$ proposed preservation of the chordae tendineae and the division of the anterior leaflet into 2 segments, that were displaced and reattached to the mitral annulus of their respective commissural areas. Buffolo et $\mathrm{al}^{4}$ proposed that, in the treatment of DCM, the anterior leaflet chordae could be anchored in commissural areas to reduce the $\mathrm{LV}$ longitudinal axis and reestablish its elliptical shape.

The papillary muscles play an important role in ventricular contraction. Secured by the atrioventricular ring, these muscles approximate the anterolateral and posteromedial walls during systole, thus, determining the degree of longitudinal axis lessening and modification of the spheroid ventricle ${ }^{20}$.

The technique we use to treat DCM maintains chordae tension inside the left ventricle by displacing excess chordae tendineae to the left atrium. This surgical strategy moves 1 step closer to lessening the LV longitudinal axis and inducing return of its elliptical form. The traction, adequate positioning and anchoring of the chordae tendineae at 4 points in the atrioventricular ring should disperse, in a more physiologic manner, the papillary muscle forces that act on the ventricular wall. This break in LV wall expansion during diastole, in the absence of volume overload after correction of valve insufficiency, can create conditions that further reduce the LV longitudinal axis, cause regression of the spherical form and improve systolic function.

The echocardiographic data suggest that this possibility may explain the postoperative improvement in EF in 6 patients. When we analyzed alterations in the LV segments' contractility, we saw improved regional contraction of the walls related to the papillary muscles; this improved contractility was of variable intensity and most commonly involved the anterolateral wall. Potentially, this recuperation of regional contractility explains the increase in the EF observed in most patients. Through analysis of LV cavity geometry, we also noted a tendency of the left ventricle to regress from the spherical shape observed preoperatively. This return toward the original elliptical shape of the LV may reflect an increase in parietal systolic thickness, as demonstrated in the 2-D echocardiogram, and a reduction in the LV transverse diastolic diameter.

Patients in the last stages of DCM and FMI have disease attributable to different etiologies. Thus, it is possible that, even with the same treatment, patient outcomes may differ. A high incidence of Chagas' cardiomyopathy exists in our continent. We believe that application of this surgical technique to carefully selected patients with Chagas' cardiomyopathy may produce favorable results.

Our early results do not permit definitive conclusions, as our sample size was small and the postoperative followup time was not long. However, the good clinical evolution of these patients justifies the continued application of this technique, particularly in patients with FC IV, that is associated with high mortality.

\section{References}

1. Blondheim DS, Jacobs LE, Kotler MN, Costacurta GA, Parry WR. Dilated cardiomyopathy with mitral regurgitation: decreased survival despite a low frequency of left ventricular thrombus. Am Heart J 1991; 122: 763-71.

2. Stevenson LW, Fowler MB, Schroeder JS, Stevenson WG, Dracup KA, Fond V. Poor survival of patients with idiopathic cardiomyopathy considered too well for transplantation. Am J Med 1987; 83: 871-6.

3. Bolling SF, Pagani FD, Bachi DS. Intermediate mitral reconstruction in cardiomyopathy. J Thorac Cardiovasc Surg 1998; 115: 381-8.

4. Buffolo E, Machado IAP, Palma H, Rodrigues JNB. Nova abordagem cirúrgica para o tratamento de pacientes em insuficiência cardíaca refratária com miocardiopatia dilatada e insuficiência mitral secundária. Arq Bras Cardiol 2000; 74: 129-34.
5. Puig LB, Gaioto FA, Oliveira Jr JL, Oliveira AS. Insuficiência mitral, miocardiopatia dilatada e insuficiência cardíaca - tratamento cirúrgico. XII Congresso Norte/Nordeste de Cirurgia Cardiovascular - João Pessoa, PA, 2000.

6. Guiraudon GM, Ofiesh JG, Kaushik R. Extended vertical transatrial septal approach to the mitral valve. Ann Thorac Surg 1991; 52: 1058-62.

7. Keogh AM, Freund J, Baron DW, Hickie JB. Timing of cardiac transplantation in idiopathic dilated cardiomyopathy. Am J Cardiol 1988; 6: 418-22.

8. Rankin JS, Feneley MP, Hickey MS, et al. A clinical comparison of mitral valve repair versus replacement in ischemic mitral regurgitation. J Thorac Cardiovasc Surg 1988; 13: 585-90. 
9. Barreto ACP, Ramires JAF. Insuficiência cardíaca: um problema de saúde pública. Rev Bras Cardiol 2000; 2: 142-7.

10. Evans RW, Orians CE, Ascher NL. The potential supply of donors. JAMA 1992; 267: 239-46.

11. Carpentier A, Chacques JC, Relland J, et al. Dynamic cardiomyoplasty at seven years. J Thorac Cardiovasc Surg 1993; 106: 42-54.

12. Dreyfus GD, Duboc D, Blasco A, et al. Myocardial viability assessment in ischemic cardiomyopathy: benefits of coronary revascularization. Ann Thorac Surg 1994; 57: 1402-7.

13. Batista RJV, Santos JLV, Takeshita N, et al. Partial left ventriculectomy to improve left ventricular function in end-stage heart disease. J Card Surg 1996; 11: 967-75.

14. Wilensky RL, Yndelman P, Cohen AL, et al. Serial electrocardiographic changes in idiopathic cardiomyoplasty confirmed at necropsy. Am J Cardiol 1988; 62: 276-83.

15. Cohn LH, Kowalker W, Bhatia S, et al. Comparative morbidity of mitral valve re- pair versus replacement for mitral regurgitation with and without coronary artery disease. Ann Thorac Surg 1988;45: 284-90.

16. Bolling SF, Pagani FD, Bachi DS. Early improvement in congestive heart failure after correction of secondary mitral regurgitation. Am Heart J 1995; 129: 1165-70.

17. Callafiore AM, Sabina G, Gallina MD, et al. Mitral valve procedure in dilated cardiomyopathy: repair or replacement? Ann Thorac Surg 2001; 71: 146-53.

18. Lillehei CW, Levy MJ, Bonnebeau MB. Mitral valve replacement with preservation of the papillary muscles and the chordae tendineae. J Thorac Cardiovasc Surg 1964; 47: 532-43.

19. Miki S, Kusuhara K, Ueda Y, Komeda M, Orkita Y. Mitral valve replacement with preservation of chordae tendineae and papillary muscles. Ann Thorac Surg 1988; 45: 28-34.

20. Rushmer RF, Finlayson BL, Nash AA. Movements of mitral valve. Circ Res $1956 ; 4: 337$. 